\section{The form class of word associations to nominalizations and adjectivalizations}

KATE LOEWENTHAL, Department of Social Science and Humanities, The City University, London, E.C.1, England

This experiment examined the form-class of associations to four types of stimuli: nouns, adjectives, nominalizations, and adjectivalizations. The hypothesis of the experiment, that nominalizations and adjectivalizations are coded in terms of a base item and a transforming suffix, was confirmed in that transformed words elicited responses which matched their form-class less often than base words of the same form-class do. The tendency for syntagmatic responses to adjectives to be nouns rather than words of other form-classes was noted and discussed.

The English language contains a number of words which appear to be transformations made by the addition of a suffix to a base lexical item. Briem \& Loewenthal (1968) showed that lists of two kinds of these words, nominalizations and adjectivalizations, occupy more space in immediate memory than lists of base nouns and adjectives, even though the word lists were equated for frequency of occurrence. The rationale for this finding is similar to that used by Savin \& Perchonok (1965) who found that STM space occupied by sentences could be predicted more accurately by the number of transformations they contained; this rationale is based on Chomsky (1957).

The hypothesis of the present experiment was that words which are transformations of base words are coded in terms of a base lexical item plus a transforming suffix, rather than as single lexical entities. The purpose of the experiment was to examine the form class of word associations to nouns, adjectives, nominalizations and adjectivalizations. Interest in the form-class of word associations comes largely from the observation that, whereas young children tend to give associations of a form-class different from that of the stimulus (syntagmatic responses), adults' responses are paradigmatic, of the same grammatical class as the stimulus (Ervin, 1961).

If adults' responses to all form-classes of words were equally likely to be paradigmatic, then it would be expected that nouns and nominalizations, adjectives and adjectivalizations would be equally likely to elicit responses of matching form-class. Deese (1962) has shown already that nouns are more likely than adjectives to elicit paradigmatic responses. Further differences in the form-class of responses to the four types of word used in the experiment would be expected from the hypothesis that nominalizations and adjectivalizations are coded in terms of a base item plus a transforming suffix. Thus it would be expected that nominalizations would be likely to elicit responses of the form-class of the base item from which they are derived, and thus they would be less likely to elicit noun associations than would ordinary base nouns. A similar argument applies to adjectivalizations and base adjectives.

\section{SUBJECTS}

Subjects were 44 undergraduate engineering, physics, and social science students in the City University, London, and they were run in three group sessions. There were 34 men and 10 women.

\section{MATERIALS}

The stimulus words were 8 nouns, 8 adjectives, 16 nominalizations, and 16 adjectivalizations. Eight of the adjectivalizations were derived from the nouns, and were matched with them for frequency of occurrence (Thorndike \& Lorge, 1944). Similarly, 8 of the nominalizations were derived from the adjectives, and were matched with them for frequency of occurrence. The remaining 8 nominalizations paired with the remaining 8 adjectivalizations, in that each member of the pair was derived from the same underlying base, usually a verb, and the members of each pair were matched for frequency of occurrence. The nominalizations and adjectivalizations were chosen so as to show as wide a variety of suffixes as possible.

\section{PROCEDURE}

Each $S$ received the list of 48 words in the same scrambled order, with printed instructions at the head of the page "to read the words one by one, and to write beside each word the first word it makes you think of."

\section{RESULTS}

There were 79 (out of a possible 2,112) failures to give an association. The word associations were classified "blind" (i.e., without knowledge of the form-class of the stimulus word) as nouns, adjectives, or "other." Associations of ambiguous form-class were fortunately rare, and so these were not classified separately but were assigned to the form-class of what in the opinion of the judge was their most commonly used sense. Table 1 gives the mean per cent of responses of different form-classes to the four types of stimulus. The figures of $78 \%$ noun responses to nouns and $51.9 \%$ adjective responses to adjectives agree very closely with the figures of $79 \%$ and $50 \%$, respectively, which can be deduced from Deese (1962).

Analysis of variance on the per cent of noun responses showed significant differences between noun-type (noun + nominalizations) and adjective-type (adjective + adjectivalizations) stimuli $[F(1,44)=20.14, p<0.001]$. Differences between base and transformed words were not significant, but the interaction (Noun-type vs Adjective-type by Basic vs Transformed) was significant at the 0.01 level $[F(1,44)=8.27]$. Analysis of variance on the per cent of adjective responses also showed significant differences between noun-type and adjective-type stimuli $[F(1,44)=28.02, p<0.001]$, but no other sources of variance were associated with significant differences.

It can be seen that nominalizations derived from adjectives are more likely than nominalizations derived from other bases to elicit adjective responses, and are less likely to elicit "other" responses. Similarly, adjectivalizations derived from nouns are more likely than adjectivalizations derived from other bases to elicit noun responses, and are less likely to elicit other responses. DISCUSSION

The results support the hypothesis; transformed words are less likely to elicit responses of the same form-class than are base words. There is a tendency, instead, to match the form-class of the item from which the transformed word is derived.

There seem to be three tendencies in the data: to match the form-class of the stimulus; to match the form-class of the base
Table 1

Mean Percentage of Responses of Different Form Classes

\begin{tabular}{lcccccc}
\hline & \multicolumn{3}{c}{$\begin{array}{c}\text { Nominalisation } \\
\text { Derived from } \\
\text { Adjectives }\end{array}$} & Other & Form Class of Stimulus \\
Response & Noun & Adjective & $\begin{array}{c}\text { Adjectivalisation } \\
\text { Derived from } \\
\text { Nouns }\end{array}$ & Other \\
\hline Noun & 78.0 & 62.3 & 61.0 & 33.8 & 59.4 & 38.5 \\
Adjective & 15.5 & 26.5 & 19.3 & 51.9 & 37.6 & 46.5 \\
Other & 5.0 & 11.5 & 19.5 & 14.9 & 3.0 & 15.5 \\
\hline
\end{tabular}


from which the stimulus is derived; and also to produce noun responses rather than responses of other form-classes-e.g., among the syntagmatic associations to adjectives there are more than twice as many nouns as there are responses of other form-classes.

There have been several discussions of the determinants of the form-class of word associations in the literature. Ervin (1961) derives an explanation for pardigmatic responses in adults in terms of the association-theory explanation for the production of syntagmatic responses. Syntagmatic responses of the type "deep-hole" can be explained in terms of experience of words in contiguity. Paradigmatic responses of the type "deep-shallow" can be accounted for by erroneous anticipation of "shallow" in the sort of lexical contexts which contain "deep." This explanation has been shown inadequate by McNeill (1966). It is, moreover, difficult to see how the explanation as it stands can account for the variation between stimuli of different form-classes in the likelihood of eliciting syntagmatic responses. Deese (1962) accounts for this variation in terms of the relative "independence of their verbal environments" of words of different form-classes: nouns, for instance, are relatively independent, while low-frequency adjectives depend more heavily on the environments which they modify.

McNeill's (1966) explanation of form-class matching is based on Deese's (1964) observation that paradigmatic associations form a minimal contrast with the stimulus, and on a dictionary-entry theory of semantics of the sort proposed originally by Katz \& Fodor (1963): each lexical item is characterized by an entry containing syntactic and semantic markers, and selection restrictions. $\mathrm{McNeill}$ argues that word associations are attempts to match the stimulus on as many features as possible, including syntactic features. This explanation also fails to account for variations between words of different form-class in the likelihood of eliciting paradigmatic responses; nor is the tendency to produce noun responses very well accounted for. However, the tendency for transformed words to elicit associations matching the form-class of the bases from which they are derived can be accounted for, if it is assumed that the dictionary entry for, say, the nominalization of an adjective comprises an entry for the adjective, plus, at some level, an entry for the transforming suffix.

The preference for noun responses has been considered by Marshall \& Newcombe (1966) in a study of paralexic errors in reading single words. In Marshall and Newcombe's study, where the form-class of the word was incorrectly given, there was a tendency for the erroneous word to be a noun rather than a word of another form-class. Chomsky (1965) has suggested that, in the theory of syntax, nouns are first inserted into generalized phrase-markers by context-free rules, and then verbs and adjectives are selected in accordance with the noun features. Marshall and Newcombe suggest that this argument may be applied not only to sentence production, but also to paralexic errors in single-word reading; it could also be extended to word association to account for noun-response dominance. It might even account for the differences between words of different form-class in the likelihood of eliciting paradigmatic responses. In essence, the argument may be reduced to something very like Deese's suggestion that nouns are less context-dependent than other parts of speech.

To summarize: The form-class of associations obtained in this experiment can be accounted for by the proposition that associations are attempts to match the stimulus on syntactic and semantic features. When the stimulus is a nominalization or an adjectivalization, there is a compromise between the form-class of the stimulus and the form-class of the underlying base, supporting the notion that nominalizations and adjectivalizations are coded in terms of a base and a transforming suffix. Where form-class matching breaks down, there is a regression towards noun responses.

\section{REFERENCES}

BRIEM, J., \& LOEWENTHAL, K. Immediate recall of nominalizations and adjectivalizations. Psychonomic Science, 1968, 11, 209.

CHOMSKY, N. Syntactic structures. The Hague: Mouton, 1957.

CHOMSKY, N. Aspects of the theory of syntax. Cambridge: M.I.T. Press, 1965.

DEESE, J. Form class and the determinants of association. Journal of Verbal Learning \& Verbal Behavior, 1962, 1, 79-84.

DEESE, J. The associative structure of some common English adjectives. Journal of Verbal Learning \& Verbal Behavior, 1964, 3, 347-357.

ERVIN, S. M. Changes with age in the verbal determinants of word association. American Journal of Psychology, 1961, 74, 36 1-372.

KATZ, J. J., \& FODOR, J. The structure of a semantic theory. Language, 1963, 39, 170-210.

McNEILL, D. A study of word-association. Journal of Verbal Learning \& Verbal Behavior, 1966,6, 548-557.

MARSHALL, J. C., \& NEWCOMBE, F. Syntactic and semantic errors in paralexia. Neuropsychologia, 1966, 4, 169.

SAVIN, H. B., \& PERCHONOK, E. Grammatical structure and the immediate recall of English sentences. Journal of Verbal Learning \& Verbal Behavior, 1965, 4, 348-353.

THORNDIKE, E. I., \& LORGE, I. The teacher's book of 30,000 words. New York: Columbia University Press, 1944.

\section{Effect of concept grouping and dominance level on free recall}

DENNIS M. ROBERTS and BIKKAR S. RANDHAWA, Department of Measurement and Evaluation, The Ontario Institute for Studies in Education, Toronto 5, Ontario, Canada

Lists of words were developed from Underwood \& Richardson's (1956) verbal concept formation materials that would vary (1) in terms of their overall dominance level, and (2) whether or not words within lists were related to the same adjective concept. In administering these lists in a repeated measures design, no main effects (dominance level or concept grouping) were found, but a highly significant interaction resulted. It appears that concept grouping of words into lists only facilitates words of low dominance level.

Scandura (1967) has recently shown that varying the dominance level of Underwood \& Richardson's (1956) concept formation materials results in differential recall. King, Reid, \& Roberts (1966) have shown that when lists of words are composed of different alternation patterns of dominance level, odd-shaped serial-position curves are obtained. It was also reported that no significant differences in recall were obtained when the lists of words were or were not grouped on the basis of having all words within the same list related to the same sense-impression adjective category. The previous evidence tends to support the notion that dominance level may be related or analogous to such measures as association value or Noble's (1952) $\bar{m}$. The present study was designed to further investigate whether the amount of free recall is a function of dominance level, and whether grouping nouns into concept-related or nonconcept-related lists affects recall.

\section{SUBJECTS}

Subjects were 72 psychology students at Ryerson Poly technical Institute in Toronto, Canada. The sample was predominantly male. Four separate classroom sections were used. 